\title{
The role of transcription factor Nrf2 in skin cells metabolism
}

\author{
Agnieszka Gęgotek • Elżbieta Skrzydlewska
}

Received: 13 October 2014/Revised: 6 February 2015/Accepted: 12 February 2015/Published online: 24 February 2015

(C) The Author(s) 2015. This article is published with open access at Springerlink.com

\begin{abstract}
Skin, which is a protective layer of the body, is in constant contact with physical and chemical environmental factors. Exposure of the skin to highly adverse conditions often leads to oxidative stress. Moreover, it has been observed that skin cells are also exposed to reactive oxygen species generated during cell metabolism particularly in relation to the synthesis of melanin or the metabolism in immune system cells. However, skin cells have special features that protect them against oxidative modifications including transcription factor Nrf2, which is responsible for the transcription of the antioxidant protein genes such as antioxidant enzymes, small molecular antioxidant proteins or interleukins, and multidrug response protein. In the present study, the mechanisms of Nrf2 activation have been compared in the cells forming the various layers of the skin: keratinocytes, melanocytes, and fibroblasts. The primary mechanism of control of Nrf2 activity is its binding by cytoplasmic inhibitor Keap1, while cells have also other controlling mechanisms, such as phosphorylation of $\mathrm{Nrf} 2$ and modifications of its activators (e.g., Maf, IKK $\beta$ ) or inhibitors (e.g., Bach1, caveolae, TGF- $\beta$ ). Moreover, there are a number of drugs (e.g., ketoconazole) used in the pharmacotherapy of skin diseases based on the activation of Nrf2, but they may also induce oxidative stress. Therefore, it is important to look for compounds that cause a selective activation of Nrf2 particularly natural substances such as curcumin, sulforaphane, or extracts from the broccoli leaves without side effects. These findings could be helpful in the searching for new drugs for people with vitiligo or even melanoma.
\end{abstract}

A. Gęgotek $(\bowtie) \cdot$ E. Skrzydlewska

Departments of Analytical Chemistry, Medical University of

Bialystok, Mickiewicza 2D, 15-222 Bialystok, Poland

e-mail: agnieszkagegotek@o2.pl
Keywords Nrf2 - Proteins expression - Reactive oxygen species $\cdot$ Keratinocytes $\cdot$ Melanocytes $\cdot$ Fibroblasts

\section{Introduction}

Skin cells, being in constant contact with the surrounding environment, are highly susceptible to the effects of different stimulants. UV irradiation, xenobiotics, and thermal stress disturb cell metabolism and consequently lead to the increase in reactive oxygen species (ROS) generation and to redox imbalance. UV radiation, carrying a large dose of energy, directly converts oxygen molecules in the reactive forms and/or causes damages of the cellular macromolecules structures impairing their functions [106]. However, high or low temperatures disrupt the metabolic pathways thereby causing an overproduction of ROS that leads to the decrease in the activity of heat-labile proteins, in particular [32]. Metabolism of skin cells is also altered by xenobiotics affecting ROS generation and thereby antioxidant abilities, signal transductions, and the rate of transport through membranes [31]. All the factors, leading to an increase in ROS generation and/or a reduction in the antioxidant capacity, contribute to oxidative stress, which exposes the skin cells to the formation and accumulation of irreversibly damaged proteins, lipids, nucleic acids, and carbohydrates. This leads to a visible reduction of skin conditions, aging, and dying cells and may also induce malignant transformation [121].

\section{Transcription factor Nrf2}

One of the ways to defend skin cells against oxidative stress is the transcriptional regulation of cytoprotectional genes by 
Nrf2 (Nuclear erythroid 2-related factor), in which expression in all types of epidermal cells was observed at a very high level [63]. The transcription factor Nrf2 belongs to the "cap'n'collar" (CNC) protein family, which contains the motif called leucine zipper (bZip, basic Leucine Zipper). This family has three-dimensional structures that allow the formation of dimers with other proteins containing bZip domain. The family of transcription factors containing bZIP domain is also characterized by a basic region, which binds via hydrogen bonds to the large groove of the DNA [55].

Under physiological conditions, Nrf2 encoding genes are under constant expression, as a result of which Nrf2 molecule is permanently biosynthesized. However, its level in the cytoplasm is regulated by the formation of Nrf2Keap1-Cul3 complex [107]. Keap1 binds Nrf2 and therefore directly inhibits its activity, resulting in simultaneous Nrf2 ubiquitination catalyzed by Cul3. Binding of at least four molecules of ubiquitin to Nrf2 causes degradation of this molecule by the proteasome $26 \mathrm{~S}$. However, the oxidative condition in the cell leads to the oxidation of cysteine residues in Keap1 molecule, changing the conformation of the protein and causing dissociation of Nrf2 from complex [47, 82]. Free Nrf2 cannot be ubiquitinated and degraded. In turn, it is translocated to the nucleus, where it forms a complex with a small Maf protein and then is bound to the DNA in a characteristic sequence 5'-TGACnnnGCA-3' labeled as antioxidant responsive element (ARE) and in consequence initiates the transcription of antioxidant genes (Fig. 1) [50]. Nrf2 cytoprotective action concerns mainly antioxidant enzymes such as glutathione S-transferase (GST), quinone reductase NAD(P)H (NQO1), UDP-glucuronosyltransferases (UGT), epoxide hydrolase (EPHX), $\gamma$-glutamylcysteine ligase (GCL), heme oxygenase-1 (HO-1), glutathione reductase (GR), thioredoxin reductase (TrxR), catalase (CAT), and superoxide dismutase (SOD) [76, 97, 130]. Nrf2 also activates the transcription of non-enzymatic antioxidant protein genes containing in their structure the ARE sequence (e.g., thioredoxin, ferritin) $[34,94]$. The role of Nrf2 in protecting skin cells against ROS action highlights the fact that $7 \%$ of squamous cell skin cancer in human results from mutations in Nrf2 gene [49]. Additionally, Nrf2 acts as a stimulant of anti-apoptotic proteins from Bcl-2 family [84]. The control of a wide range of antioxidants and antiapoptotic molecules causes that Nrf2 is recognized as a significant factor in the cellular response to oxidative stress, especially in the cells, which form the outer layers of the skin.

In spite of antioxidative character of Nrf2, its action may be directly modified by ROS as well as by reactive products of lipid peroxidation that influence this and cooperative proteins, particularly during oxidative stress. It was observed that low level of ROS causes the Nrf2 expression, while its high level has no effect on the Nrf2 level and leads to the irreversible cell injury and induction of apoptosis. However, it is also known that an intermediate level of ROS may participate in the control of the balance between survival and apoptosis through the activation of another transcription factor-NFkB [68, 86, 113]. Therefore, the cooperation between members of $\mathrm{NF \kappa B}$ and $\mathrm{Nrf} 2$ pathways may exist, and the cross-talk between Nrf2 and $\mathrm{NF \kappa B}$ under pathological conditions is suggested [9]. It has been shown that the Keap1/Cul3 complex could regulate both the Nrf2 and the NFkB expression through the ubiquitination. Moreover, Keap1 acts as an inducible factor for ubiquitination IKK $\beta$, which is a cytoplasmic $N F \kappa B$ inhibitor. Deletion of Keap1 leads to accumulation and stabilization of IKK $\beta$ and upregulation of NFKB-derived tumor angiogenic factors [58]. On the other hand, NFKB subunits induce transcription of Nrf2 in cells at a specific promoter $\kappa \mathrm{B}$ site and thus encourage resistance to chemotherapy-induced cytotoxicity [24, 101]. It was also reported that $\mathrm{NF \kappa B}$ competes with $\mathrm{Nrf2}$ as co-activator CREB-binding protein (CBP) [66]. Moreover, NFאB recruits histone deacetylase 3 (HDAC3) causing local hypoacetylation to hamper Nrf2 signaling [66]. However, absence of Nrf2 induces more aggressive inflammation through activation of $\mathrm{NF \kappa B}$ and downstream proinflammatory cytokines [89]. Furthermore, Keap1 interacts with

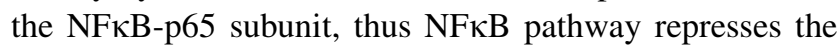
Nrf2 transcriptional activity [126]. On the other hand, both $\mathrm{NF} \kappa \mathrm{B}$ and Nrf2 regulate the same group of genes, including HO-1, GCLC, Gai2, and IL-8 [23].

Moreover, it is known that products of lipid oxidative modification generated during free radicals peroxidation as well as during enzymatic oxidation are involved in Nrf2 action. It was shown that 4-hydroxynonenal (4-HNE), one of the most reactive lipid peroxidation products, at nontoxic levels can activate stress response pathways such as Nrf2/ ARE by changing Keap1 conformation [38, 109]. What is more, cell stimulation with 4-HNE at sublethal level induces adaptive response and enhances cell tolerance, primarily through induction of thioredoxin via transcriptional activation of the Nrf2 signaling pathway, thereby protecting cells against the forthcoming oxidative stress [12]. However, ROS leads to increased expression of cyclooxygenases (COX) that oxidizes arachidonic acid to $\mathrm{PGH} 2$ that is further metabolized by specific PG isomerases to PGE2, PGD2, PGF2 $\alpha$, TXA2, and prostacyclin I2 [118]. Dehydration of PGD2 leads to generation of a reactive 15d-PGJ2 that exhibits a unique spectrum of biological effects, including inhibition of I $\kappa$ B-kinase- $\beta$ [99] and induction of glutathione S-transferase gene expression and apoptosis [53]. Moreover, 15d-PGJ2 may form adducts with Keap1 simultaneously causing dissociation of Nrf2 from complex [25]. This mechanism of Nrf2 activation was investigated in both keratinocytes and melanocytes [44, 56]. 


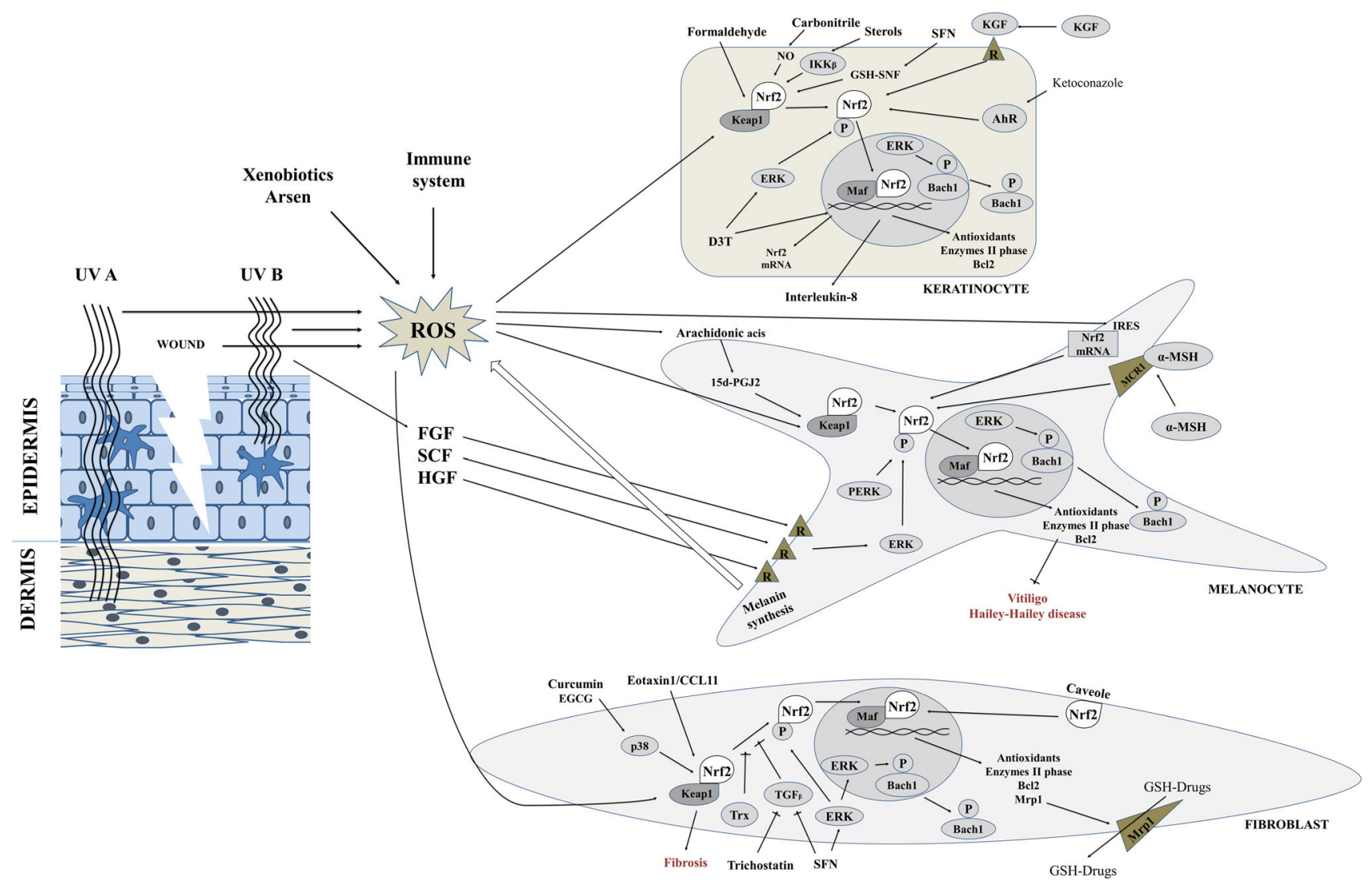

Fig. 1 Nrf2 activation pathways in the different skin cells: keratinocyte, melanocyte, and fibroblast. $P$ phosphorylation and $R$ receptor

\section{Epidermis}

The skin consists of three layers: epidermis, dermis, and hypodermis. The epidermis is the outermost layer of the skin having hydrophobic properties. It is formed mainly from keratinocytes, but it also consists dye cells-melanocytes, Langerhans cells - the cells responsible for immune reactions, and Merkel cells—cells of the nervous system.

\section{Nrf2 in keratinocytes}

The first line of human body contact with the environment creates keratinocytes. In order to ensure skin's resistance to external factors, the deep layers of the epidermis must have a high rate of normal cells proliferation, without disturbance in the structure and functioning. It is believed that the high resistance of the skin to external factors and its quick response to damages are related to the presence of specific receptors for growth factor (KGF-Keratinocyte Growth Factor) on the surface of keratinocytes, produced by mesenchymal cells. KGF is a small protein that can bind to the specific receptors on the keratinocytes cell membrane, which is a simultaneous signal to proliferation and to create a new layer of the epidermis at the injured place. The precise mechanism of KGF action is not completely described yet, but a direct effect of KGF on the increase of the Nrf2 activity was proposed [8]. However, Nrf2-dependent gene expression can affect the survival, differentiation, and premature death of these cells [60]. It ensures dividing the cells resistant to mutations caused by increased levels of ROS. Moreover, the increase in Nrf2 activity during keratinocytes differentiation was observed and was confirmed by the fact that in the surficial layers of the epidermis, which are the most vulnerable to external factors and are faster keratinized than younger cells, there is a higher level of antioxidant enzymes whose expression is dependent on the Nrf2 activity [60, 92].

As in other cells, in keratinocytes, ROS are generated during aerobic metabolism as well as through metabolism (mainly "respiratory burst") of the immune system cells, which are common in the epidermis [122]. ROS, which are generated in order to protect the skin against pathogens, expose keratinocytes to depletion of antioxidant abilities and oxidative modifications of cellular components, including transcription factor Nrf2. Interactions between keratinocytes and immune system cells affect not only ROS generation, but also the efficient action of immune 
system [30]. Keratinocytes, as well as fibroblasts, belong to the group of cells that can produce interleukins. Interleukin-8 (IL-8) is one of the proteins whose expression is ARE dependent, and thus its level depends on the Nrf2 activity [98]. Through the release of interleukin- 8 to the intercellular space, keratinocytes and fibroblasts provide communications in the whole body and fast response of the immune system to contact the harmful chemicals [127]. Increased IL-8 generation by keratinocytes is also observed in the case of mechanical skin damage. It is probably linked with the Nrf2 activation induced by oxidative stress in keratinocytes adjacent to the wound [14]. Nrf2 is also responsible for the release of others inflammatory mediators (e.g., IL-6, IL-1 $\beta$, and GM-CSF) in the case of allergic contact of dermatitis. Studies of the keratinocytes line $\mathrm{HaCaT}$ response to allergens show that through activation of MAP kinase, Nrf2 is translocated to the nucleus. Consequently, an increase in interleukin release is observed, but the mechanism of this reaction has not yet been completely examined [74].

As ROS can interfere with the aging process and differentiation of keratinocytes, the maintenance of high levels of antioxidant enzymes (mainly HO-1, NQO1, and GST) is important for these cells. Therefore, the high activity of Nrf2 results from the activation of Nrf2, by dissociation of Nrf2-Keap1 complex, prevents deformation during keratinocyte differentiation and even malignant transformation [5, 92]. In the case of changing in level of another Nrf2 inhibitor-Bach1, which competes with Nrf2 for binding to the DNA, prevention of malignant transformation was not observed [70]. It has been shown that in Keap1-knockout mice keratinocytes, the control of transcriptional activity can be taken care of by a small protein Maf. In the case when there is no Nrf2 inhibitor, Keap1 in the cytoplasm, active, and uncontrolled Nrf2 is translocated to the nucleus, where, only after Maf-Nrf2 complex formation, it can bind DNA and initiate transcription of the genes. Therefore, in the Keap1-knockout mice keratinocytes, response to stress factors and the rate of skin aging depend on the level of Maf protein in the nucleus [79].

Disturbances in the Nrf2 activity may lead to development of various diseases. Allergic contact dermatitis (ACD) is induced usually by low molecular weight of electrophilic chemicals and metal ions, and Nrf2 is one of the key molecules that transmits a signal of disturbed redox balance and causes a biological response in dendritic cells, as well as in keratinocytes, which are in contact with them. It was shown that Nrf2 is activated by chemical sensitizers in contact dermatitis and also plays a significant role in the inflammatory immune responses [1, 48], which suggests that Nrf2 could be implicated in the chemical sensitization processes [18]. Therefore, important role of Nrf2 in controlling ACD in response to sensitizers is suggested [19].
Moreover, it is demonstrated that Nrf2 activation in keratinocytes is one of the objectives of coal tar application in case of atopic dermatitis (AD) [115]. Topical application of coal tar is one of the oldest therapies for AD. It was also found that coal tar activates the aryl hydrocarbon receptor (AhR), which can bind to the Nrf2 gene locus and increase its expression [116]. As a result, higher Nrf2 level leads to induction of NQO1 transcription [40, 116].

\section{Extracellular Nrf2 activators in keratinocytes}

Oxidative stress in keratinocytes may be generated by xenobiotics, e.g., arsenic, which is an inducer of carcinogenesis in HaCaT cell line. Increased ROS generation (mainly hydrogen peroxide) lead to the increase in Nrf2 expression, at transcription and translation level, as well as the accumulation of active Nrf2 in the nucleus of those cells [91]. Xenobiotics strongly sensitizing skin such as formaldehyde, eugenol, or dinitrochlorobenzene elicit the skin's defences through Nrf2 activation. As a result of covalent links between these compounds and the cysteine residues in Keap1, Nrf2 dissociates from Nrf2-Keap1-Cul3 complex and consequently begins the ARE-dependent gene expression [10, 78]. Many chemopreventive phytochemicals are known to activate Nrf2 either by oxidative or covalent modification of its cytosolic repressor-Keap1 or by phosphorylation of Nrf2 [15].

Nrf2 also protects skin cells from UV radiation. Overexpression of the Nrf2 gene in mice skin keratinocytes exposed to UVB radiation causes higher resistance to apoptosis [54]. Incubation of the keratinocytes line $\mathrm{HaCaT}$ with flavonoids, such as quercetin or kaempferol, significantly protects cells against UV radiation with the increase of Nrf2 level in the cytoplasm and cells viability $[45,51]$. Therefore, there is a constant search for a highly selective activator of Nrf2 in keratinocytes that not induce side effects. A promising compound of natural origin is sulforaphane (SFN) isolated mainly from cruciferous plants such as broccoli or brussels sprouts [103]. Mechanism of SFN action involves a reduction in the GSH level, which in turn alters the Keap1 conformation and its inhibitory properties, and consequently the active Nrf2 is released into the cytoplasm [80,120] and enhances the expression of antioxidant enzymes (NQO1, HO-1, $\gamma$ GCS) in keratinocyte line HaCaT [121]. The extract containing the SFN reduces the risk of carcinogenesis induced by UV radiation in mice line SKH-1 [16]. Moreover, the abovementioned extract given to animals with benign tumor of the skin reduced the tumor weight [104]. However, studies conducted on volunteers subjected to UV light and treated with SFN showed a decrease in the development of skin erythema up to $90 \%$ [111]. 
Nrf2 activity may also be indirectly affected by the plant sterols (e.g., (Z)-guglesterone). Their action is associated with the activation of $\mathrm{I} \kappa \mathrm{B}$, whereby its physiological activator IKK $\beta$ may remain in an inactive form and bind to Keap1, thereby blocking Nrf2 ubiquitination and increasing the level of active Nrf2 in cells [2]. Other compounds that could activate Nrf2 are carbonitriles whose metabolism increased NO level and can lead to nitrosylation of Keap1 cysteine's. This modification alters the conformation of Keap1 and leads to a release of Nrf2 into the cytoplasm [65]. Another natural compound that enhances Nrf2 mRNA level and phosphorylation by ERK kinases that leads to increase in the transcriptional Nrf2 activity is D3T (3H-1,2-dithiole-3-thione) [57, 72]. It is also suggested that dietary supplements containing ellagic acid are based on the activation of Nrf2. It was shown that ellagic acid results in a higher cells survival after UVA radiation. Furthermore, these cells exhibited a higher resistance to ROS generation and cellular components oxidative modifications, which may be associated with increased expression of antioxidant enzymes (HO-1 and SOD) [36].

The mechanism of certain drugs action on epidermal keratinocytes (NHEK) is also associated with Nrf2 activation [116]. Ketoconazole, an antifungal agent from the group of azoles, activates the cytoplasmic receptor AhR and forms with them active transcription complex, which is translocated to the nucleus where it binds DNA and initiates gene expression $[11,69]$. It is directly related to the increase in the transcriptional Nrf2 activity, and therefore a reduction of the inflammatory response but the exact mechanism of the intersection of these two pathways is not fully understood yet [52].

\section{Nrf2 in melanocytes}

Except the keratinocytes, the epidermal layer includes also melanocytes. They are distributed mainly near the basal membrane of the epidermis. Melanocytes are small cells with a low content in the central and have numerous long cytoplasmic appendixes, which penetrates the layers of keratinocytes. There are two types of beans stored inside these appendixes: melanosomes-capable to synthesizing melanin and melanin grains. Melanin is responsible for the dark pigmentation of human skin, thereby protecting the deeper layers of the skin from UV radiation that is also a stimulator of the melanin synthesis [85]. During melanogenesis, tyrosinase, the major tyrosine metabolism enzyme, may show diphenolaze $\left(\mathrm{H}_{2} \mathrm{O}_{2}\right.$ generation) or catalase $\left(\mathrm{H}_{2} \mathrm{O}_{2}\right.$ decomposition) activity. Therefore, the synthesis of melanin may be associated with higher ROS generation [112]. Nrf2 activity protects melanocytes against the harmful ROS effects. It has been shown that overexpression of Nrf2 caused by transfection of plasmids containing the Nrf2 gene (pCMV6-XL5) or Keap1 mRNA silencing using siRNA prevents oxidative stress induced by xenobiotics in melanocytes cell line PIG1 or NHK [41, 73]. Furthermore, ex vivo studies have shown that enhanced level/activity of Nrf2 and protein whose synthesis is dependent on this factor reduces the effects of oxidative stress formed after exposure to UVB radiation. Nrf2 activation mechanism in melanocytes is associated with a higher level of melanotropine ( $\alpha$-MSH) - the hormone produced in the pituitary gland, whose binding to a specific receptor on the surface of melanocytes (MC-1R), leads to the formation of complexes initiating ARE-dependent genes transcription [54]. Other studies show that the increased level of active Nrf2 is directly related to the IRES sequence (internal ribosome entry sequence) contained in the Nrf2 transcript, which is responsible for transcription-dependent redox state [95]. This transcript receives a signal from the cytoplasm about the unbalanced redox status and begins synthesis of the new Nrf2 molecules [104].

There is a strong evidence suggesting influence of the degree of phosphorylation on the Nrf2 activity. As a result of oxidative stress, Nrf2 is dissociated from Keap1-Nrf2 complex and then as a free molecule can be phosphorylated. On the other hand, it is known that expression of many kinases (mainly MAPK family, PI3K) is increased during oxidative stress; therefore, the level of phosphorylated Nrf2 is also rapidly increased [108]. Moreover, Nrf2 is phosphorylated by kinase ERK1/2 activated on Ras/Raf/ MEK/ERK signaling pathway [59]. On the other hand, ERK activation in nucleus can lead to phosphorylation of Bach1-protein, which under physiological conditions binds DNA in a sequence of ARE, blocking the Nrf2 activity. Phosphorylated Bach1 loses the ability to bind to DNA and allows Nrf2 to start the transcription and antioxidant protein synthesis, whereby cells become highly resistant to the oxidative stress induced by UV radiation [129]. Additionally, the level of phosphorylated Nrf2 is increased by phenolic compounds that activate the PERK kinase [114].

The number of melanocytes in the skin of people of different races is similar, and the differences in color are only due to the intensity of the melanin production. It is estimated that the epidermal ratio of melanocytes to keratinocytes is around 1-40 (depending on the part of the body). After exposure to UV radiation, the amount and the activity of the melanocytes are regulated by keratinocytes through the synthesis and release of signaling compounds (e.g., FGF, SCF, HGF) into the intercellular space [35]. These molecules are paracrine growth factors, and after binding one of them to specific receptors (FGFR1/2, c-kit, c-Met), the activation of signaling cascade pathway is responsible for cell proliferation, differentiation, and 
motility, as well as the initiation of intensity of melanin synthesis [17].

Melanocytes, during the whole period of life, retain the ability to proliferate, as a result of adaptation to changing environmental conditions associated with the intensity of solar radiation throughout the year [27]. Furthermore, the melanocytes are highly sensitive to apoptosis caused by chemical signals caused by bacterial toxins, microtubule structure damaging substances, or protein synthesis inhibitors [37]; therefore, their reduction must be complemented by continuously proliferating cells. However, generated during proliferation and continuously accumulated errors in the genome lead to uncontrolled proliferation of cells and start the process of carcinogenesis, which leads to the development of malignant melanoma [39]. In addition, the constant oxidative stress associated with exposure to radiation, changes in temperature, and the effect of xenobiotics cause the accumulation of oxidative damages in these cells. Therefore, high level of Nrf2 synthesis is constantly maintained in melanocytes [41]. Studies show that disturbances in the synthesis or activation of Nrf2 reduce the resistance of cells to stress, both physical and chemical, leading to cell death or to carcinogenesis [42]. Regardless of the influence of above factors, Nrf2 activity is also dependent on the Maf-nuclear protein level and chemical structure that may be affected by viral infections of the skin. This causes an increase in the intensity of Nrf2-Maf transcription complex formation and their strength of DNA binding, which can lead to uncontrolled antiapoptotic protein overexpression and consequently even to the process of carcinogenesis [62].

\section{Extracellular Nrf2 activators in melanocytes}

Nrf2 is also involved in response of the skin to many diseases, e.g., in the case of Hailey-Hailey disease (bullous disease, HHD); subcutaneous injection of afamelanotide causes the increase of active Nrf2 level in melanocytes and keratinocytes that result in a reduction in the level of ROS and local inflammation [7]. Activation of Nrf2 may also be associated with genetic anomalies. It has been shown that the incidence of vitiligo in humans depends on an Nrf2 gene set. In people with vitiligo, significantly lower levels of Nrf2 m-RNA compared to healthy subjects were reported [3]. Depending on the activity of newly generated Nrf2, resistance of melanocytes to oxidative stress and the risk of vitiligo are changed [26, 42]. Furthermore, in melanocytes from patients treated with curcumin, a strong increase in phase II enzymes synthesis is observed, but simultaneously it results in increase in the apoptosis in the keratinocytes [81].

\section{Dermis}

Dermis mainly consists of fibroblasts, which are located between the connective tissue (collagen and elastin fibers), nerves, and blood vessels. These cells are responsible for the synthesis and secretion of collagen, elastin, hyaluronic acid, or glycosaminoglycans into the intercellular space, thus providing strength and elasticity of the skin. Being in the middle layer of the skin, fibroblasts are not directly (as keratinocytes) exposed to the environmental factors. These cells during the whole life have a possibility to proliferate, especially in case of damage of the dermis, but unfortunately with age their activity slows down. This is accompanied by a reduction in metabolic capacity and decrease in the rate of replication, which causes the weakening and the disappearance of the skin-supporting elements. According to the free radical theory of aging, these changes are attributed to ROS action.

\section{Nrf2 in fibroblasts}

Under physiological conditions, Nrf2 controls the proper functioning of the fibroblasts. Studies on mouse embryonic fibroblasts (MEFs) show that knockdown of Nrf2 genes expression leads to a reduction in glutathione levels up to $80 \%$ relative to wild-type cells [33]. In consequence, knockdown of Nrf2 genes expression in mice fibroblasts significantly reduces their resistance to oxidative stress and survival [43], and fibroblasts derived from Nrf2 knockout mice also exhibit a much lower resistance to oxidative stress as compared to cells derived from control animals [130].

Because of epidermal layer, UVB radiation does not reach the dermis, but fibroblasts still can be exposed to UVA. Experiments on fibroblasts show that in these cells the Nrf2 activation occurs in varying degrees after exposure to different UVA wavelengths that induce a strong immune response, simultaneously leading to the transcription of many phase II antioxidant enzymes [75]. However, UVB radiation does not cause such a reaction, thereby leading to DNA damage and apoptosis, and the link between Keap1-Nrf2 pathway and apoptosis in fibroblasts was shown [46]. Tests on the mouse fibroblasts line L929 showed that $\mathrm{H}_{2} \mathrm{O}_{2}$-induced oxidative stress leads to the activation of Nrf2 and induction of antioxidant gene expression, as well as to increase in the level of anti-apoptotic proteins from Bcl-2 family [46]. It was shown that fibroblasts with $\mathrm{Bcl}-2$ gene silencing and fibroblasts incubated with an inhibitor of Bcl-2 protein (HA14-1) have reduced level of active Nrf2 [67]. However, the inhibitor of Keap1-Cul3 complex formation affects the process of 
apoptosis by binding to $\mathrm{Bcl}-2$ and its ubiquitination that reduces the antiapoptotical potential of cells [83].

Fibroblasts are characterized by two different mechanisms for the inactivation of the transcription factor Nrf2. Except for the cytoplasmic inhibitor, Keap1, fibroblasts also have a second mechanism of binding and inactivation of Nrf2 using a caveolae that are a vesicular structures formed by a dent fibroblast cell membranes [117]. They are also observed in adipocytes and endothelial cells, and their main function is to participate in membrane trafficking and endocytosis [100]. Therefore, it is believed that they can also take part in the degradation of factor $\mathrm{Nrf} 2$, but the exact mechanism of Nrf2-caveolae interaction has not yet been elucidated [64]. Dual mechanism of Nrf2 binding existing in fibroblasts probably allows cells to increase the pool of this factor in the cytoplasm under physiological conditions and thus to faster and stronger immune response to oxidative stress conditions.

Fibroblasts are cells able to differentiate. Cell culture studies suggest that inhibition of Nrf2 activity by treating cells with TGF- $\beta$ leads to an increase in the level of ROS that can cause fibrosis and fibroblast differentiation to miofibrocytes [121]. However, the level of endogenous TGF- $\beta$ as well as fibrosis process can be inhibited by Nrf2 activators such as SFN or trichostan that enhance Nrf2 binding to DNA [128]. The Nrf2 level/activity may also be affected by hormonal signaling molecules including ERR $\alpha$ (estrogen-related receptor $\alpha$ ), but the mechanism of their interaction has not been found yet [96]. One of the betterknown Nrf2 activation mechanisms used in the treatment of skin diseases is the action of curcumin. Therefore, curcumin, a turmeric root extract, has been demonstrated to induce antifibrotic cell activity. Curcumin disturbs the TGF- $\beta$ signaling in systemic scleroderma (SSc), by counteracted phosphorylation of Smad2 and induced upregulation of TGF- $\beta$-induced factor (TGIF) - a negative regulator of TGF- $\beta$ signaling. Moreover, curcumin-mediated Nrf2 activation leads to a decrease in the level of ROS that can cause suppression of fibrotic process in scleroderma [110, $122,123]$.

\section{Nrf2 activators in fibroblasts}

The activity of fibroblast Nrf2 is also reduced by thiol antioxidants such as thioredoxin that free thiol group may prevent Keap1 oxidation, which favors the maintenance of Nrf2 in Keap1 complex. However, during oxidative stress, the level of antioxidants including thioredoxin is reduced, and its effect on Nrf2 is abolished [90]. Other natural compounds that affect the activity of Nrf2 are eotaxins. Eotaxin-1/CCL11 is a natural chemokine, which appears in the intracellular matrix as a response to occurrence of stress. This chemokine increases the activity of Nrf2 in cultured fibroblasts [22], while in skin cells, patients with atopic skin eotaxin-1/CCL11 level are reduced which is contributed to the reduced activity of Nrf2 and decreased antioxidant skin cells capacity [88].

The Nrf2 activity is also involved in Mrp family expression (multidrug resistance-associated proteins) [71]. Mrp proteins are ATP-dependent membrane transporters, and their main function is to remove, from the cell, glutathione conjugates with harmful substances-mainly metabolites of drugs [61]. The highest Mrp level is noted in the hepatocytes, but in the skin fibroblasts, the level of these proteins is also high [87]. Studies on fibroblasts isolated from Nrf2 knockout mice (-/-) show that MRP1 transcript level in these cells was significantly lower compared to the control cells. Moreover, in fibroblasts Nrf2 $(+/+)$ treated with diethyl maleate, increase in the Mrp1 level was observed, while in the case of fibroblasts Nrf2 $(-/-)$, there was no such reaction [29]. Those results indicate that $\mathrm{Nrf} 2$ in fibroblasts has influence on both constitutive and inducible Mrp family expression.

The fibroblasts Nrf2 activity is also modified by many others natural compounds including polyphenols, such as curcumin, EGCG (epigallocatechin-3-gallate) or apomorphine, and flavone derivatives as well as components of pepper betle, brassica plants, and walnut sprouts extracts [28]. Polyphenols affect Nrf2 activity by effecting signaling pathways associated with p38, B-Raf, and NF- $\kappa \mathrm{B}$ [4, 77]. However, flavone derivatives enhance Nrf2 level/ activity by increase in fibroblast line NIH3T3 Nrf2 mRNA level and in active Nrf2 via activation of ERK1/2 [21, 102]. Natural Nrf2 activators are also found in the brassica plants. One of these compounds which increases the activity of $\mathrm{Nrf} 2$ and not causes toxic effects on NIH3T3 cells is 3,3-diindolylometan which is derived from indol-3-carbinol fermentation [20]. Walnut sprouts extracts also contain natural Nrf2 activators that cause an increase in cells resistance to oxidative stress and increase survival up to $50 \%$ in the case of fibroblast cells exposed to UVB [13].

\section{Uncontrolled activation of $\mathrm{Nrf} 2$ in skin cells}

Most of the results suggest rather beneficial effects of Nrf2 activation under physiological conditions. However, Nrf2 activity is inhibited by Keap1, and deletion of this second protein gene in mice caused death of these animals within the first 3 weeks after birth due to hyperkeratosis in the esophagus and stomach, resulting in nutrient obstruction and stomach ulceration. These mice also revealed severe scaling and hyperthickening of the cornified layer of the epidermis [79, 119]. It was also shown that chronic Nrf2 
activation causes sebaceous gland enlargement and seborrhea in mice keratinocytes due to upregulation of the growth factor epigen, which was identified as a novel Nrf2 target [105]. It was accompanied by thickening and hyperkeratosis of hair follicle infundibula. These abnormalities caused dilatation of infundibula, hair loss, and cyst development upon aging. Upregulation of epigen, secretory leukocyte peptidase inhibitor (Slpi), and small proline-rich protein $2 \mathrm{~d}$ (Sprr2d) in hair follicles was identified as the likely cause of infundibular acanthosis, hyperkeratosis, and cyst formation. These alterations were highly reminiscent to the phenotype of metabolizing acquired dioxin-induced skin hamartomas (MADISH) patients. Indeed, Slpi, Sprr2d, and epigen were strongly expressed in cysts of MADISH patients and upregulated by dioxin in human keratinocytes in an Nrf2-dependent manner. These results identify novel Nrf2 activity in the pilosebaceous unit and a role of Nrf2 in MADISH pathogenesis [105]. Other findings suggest that the constitutive activation of Nrf2 in the epidermis and its binding to the promoters of differentiation-specific genes in keratinocytes may lead to abnormal enhancement of keratinocytes [6].

\section{Summary}

The protection of proper skin functions needs cooperation of different mechanisms. One of them protects cellular components against oxidative damages by antioxidant proteins biosynthesis which is dependent on transcription factor Nrf2 activity (Fig. 1). The increase in the activity of Nrf2 enhances cell resistance to oxidative stress caused by UV and chemicals and in consequence could prevent malignant transformation. Nrf2, especially in keratinocytes and melanocytes, protects these cells against mutation during process of keratinization and melanogenesis. However, fibroblast Nrf2 plays an important role in protection of these cells against differentiation and fibrosis. Moreover, Nrf2 participation in wound healing and inflammation inhibition is also essential for maintaining the integrity of the skin.

Open Access This article is distributed under the terms of the Creative Commons Attribution License which permits any use, distribution, and reproduction in any medium, provided the original author(s) and the source are credited.

\section{References}

1. Ade N, Leon F, Pallardy M, Peiffer JL, Kerdine-Romer S, Tissier MH, Bonnet PA, Fabre I, Ourlin JC (2009) Hmox1 and Nqo1 genes are upregulated in response to contact sensitizers in dendritic cells and THP-1 cell line: role of the Keap1/Nrf2 pathway. Toxicol Sci 107:451-460
2. Aggarwal BB, Shishodia S (2006) Molecular targets of dietary agents for prevention and therapy of cancer. Biochem Pharmacol 71:1397-1421

3. Amin IM, AbuZeid OM, Rashed LA (2013) Tissue level of nuclear factor-erythroid2-related factor2 and melanocyte-stimulating hormone in vitiligo patients. J Egypt Wom Dermatol Soc 10:89-93

4. Andreadi CK, Howells LM, Atherfold PA, Manson MM (2006) Involvement of Nrf2, p38, B-Raf, and nuclear factor- $\kappa \mathrm{B}$, but not phosphatidylinositol 3-kinase, in induction of hemeoxygenase-1 by dietary polyphenols. Mol Pharmacol 69:1033-1040

5. Auf dem Keller U, Huber M, Beyer TA, Kümin A, Siemes C, Braun S, Bugnon P, Mitropoulos V, Johnson DA, Johnson JA, Hohl D, Werner S (2006) Nrf transcription factors in keratinocytes are essential for skin tumor prevention but not for wound healing. Mol Cell Biol 26:3773-3784

6. Beyer TA, auf dem Keller U, Braun S, Schafer M, Werner S (2007) Roles and mechanisms of action of the Nrf2 transcription factor in skin morphogenesis, wound repair and skin cancer. Cell Death Differ 14:1250-1254

7. Biolcati G, Aurizi C, Barbieri L, Cialfi S, Screpanti I, Talora C (2013) Efficacy of the melanocortin analogue Nle4-D-Phe7- $\alpha$ melanocyte-stimulating hormone in the treatment of patients with Hailey-Hailey disease. Clin Exp Dermatol 39:168-175

8. Braun S, Hanselmann C, Gassmann MG, auf dem Keller U, Born-Berclaz C, Chan K, Kann YW, Werner S (2002) Nrf2 transcription factor, a novel target of keratinocyte growth factor action which regulates gene expression and inflammation in the healing skin wound. Mol Cell Biol 22:5492-5505

9. Buelna-Chontal M, Zazueta C (2013) Redox activation of Nrf2 \& NF-кB: a double end sword? Cell Signal 25:2548-2557

10. Cao YP, Ma PC, Liu WD, Zhou WQ, Tao Y, Zhang ML, Li LJ, Chen ZY (2012) Evaluation of the skin sensitization potential of chemicals in THP-1/keratinocyte co-cultures. Immunopharmacol Immunotoxicol 34:196-204

11. Casley WL, Ogrodowczyk C, Larocque L, Jaentschke B, LeBlanc-Westwooda C, Menziesa JA, Whitehousea L, Heffordac MA, Aubinac RA, Thornd CF, Whiteheadd AS, Liac X (2007) Cytotoxic doses of ketoconazole affect expression of a subset of hepatic genes. J Toxicol Env Heal A 70:1946-1955

12. Chen ZH, Saito Y, Yoshida Y, Sekine A, Noguchi N, Niki E (2005) 4-Hydroxynonenal induces adaptive response and enhances PC12 cell tolerance primarily through induction of thioredoxin reductase 1 via activation of Nrf2. J Biol Chem 280:41921-41927

13. Choi JY, Choi DI, Lee JB, Yun SJ, Lee DH, Eun JB, Lee SC (2013) Ethanol extract of peanut sprout induces Nrf2 activation and expression of antioxidant and detoxifying enzymes in human dermal fibroblasts: implication for its protection against UVB-irradiated oxidative stress. Photochem Photobiol 89:453-460

14. Chou CC, Riviere JE, Monteiro-Riviere NA (2002) Differential relationship between the carbon chain length of jet fuel aliphatic hydrocarbons and their ability to induce cytotoxicity vs. interleukin-8 release in human epidermal keratinocytes. Toxicol Sci 69:226-233

15. Chun KS, Kundua J, Kundua JK, Surh YJ (2014) Targeting Nrf2-Keap1signaling for chemoprevention of skin carcinogenesis with bioactive phytochemicals. Toxicol Lett 229:73-84

16. Dickinson SE, Melton TF, Olson ER, Zhang J, Saboda K, Bowden GT (2009) Inhibition of activator protein-1 by sulforaphane involves interaction with cysteine in the cFos DNAbinding domain: implications for chemoprevention of UVB-induced skin cancer. Can Res 69:7103-7110

17. Duval C, Chagnoleau C, Pouradier F, Sextius P, Condom E, Bernerd F (2012) Human skin model containing melanocytes: 
essential role of keratinocyte growth factor for constitutive pigmentation-Functional response to $\alpha$-Melanocyte stimulating hormone and forskolin. Tissue Eng PT C Meth 18:947-957

18. El Ali Z, Gerbeix C, Hemon P, Esser PR, Martin SF, Pallardy M, Kerdine-Römer S (2013) Allergic skin inflammation induced by chemical sensitizers is controlled by the transcription factor Nrf2. Toxicol Sci 134:1-10

19. Emter R, Ellis G, Natsch A (2010) Performance of a novel keratinocyte-based reporter cell line to screen skin sensitizers in vitro. Toxicol Appl Pharmacol 245:281-290

20. Ernst IMA, Schuemann C, Wagner AE, Rimbach G (2011) 3, 3'diindolylmethane but not indole-3-carbinol activates Nrf2 and induces Nrf2 target gene expression in cultured murine fibroblasts. Free Radic Res 45:941-949

21. Ernst IMA, Wagner AE, Schuemann C, Storm N, Höppner W, Döring F, Stocker A, Rimbach G (2011) Allyl-, butyl-and phenylethyl-isothiocyanate activate Nrf2 in cultured fibroblasts. Pharmacol Res 63:233-240

22. Fourtounis J, Wang IM, Mathieu MC, Claveau D, Loo T, Jackson AL, Peters MA, Therien AG, Boie Y, Crackower MA (2012) Gene expression profiling following Nrf2 and Keap1 siRNA knockdown in human lung fibroblasts identifies CCL11/ Eotaxin-1 as a novel Nrf2 regulated gene. Respir Res 13:92-106

23. George LE, Lokhandwala MF, Asghar M (2012) Novel role of NF- $\kappa$ B-p65 in antioxidant homeostasis in human kidney-2 cells. Am J Physiol Renal Physiol 302:F1440-1446

24. Gloire G, Legrand-Poels S, Piette J (2006) NF- $\kappa B$ activation by reactive oxygen species: fifteen years later. Biochem Pharmacol 72:1493-1505

25. Gong P, Stewart D, Hu B, Li N, Cook J, Nel A, Alam J (2002) Activation of the mouse heme oxygenase- 1 gene by 15 -deoxy$\Delta 12$, 14-prostaglandin $\mathrm{J} 2$ is mediated by the stress response elements and transcription factor Nrf2. Antioxid Redox Sign 4:249-257

26. Guan CP, Zhou MN, Xu AE, Kang KF, Liu JF, Wei XD, Li YW, Zhao DK, Hong WS (2008) The susceptibility to vitiligo is associated with NF-E2-related factor2 (Nrf2) gene polymorphisms: a study on Chinese Han population. Exp Dermatol 17:1059-1062

27. Gupta PB, Kuperwasser C, Brunet JP, Ramaswamy S, Kuo WL, Gray JW, Naber SP, Weinberg RA (2005) The melanocyte differentiation program predisposes to metastasis after neoplastic transformation. Nat Genet 37:1047-1054

28. Hasan WN, Kwak MK, Makpol S, Ngah WZ, Yusof YA (2014) Piper betle induces phase I \& II genes through Nrf2/ARE signaling pathway in mouse embryonic fibroblasts derived from wild type and Nrf2 knockout cells. BMC Complement Altern Med 14:72-81

29. Hayashi A, Suzuki H, Itoh K, Yamamoto M, Sugiyama Y (2003) Transcription factor Nrf2 is required for the constitutive and inducible expression of multidrug resistance-associated protein1 in mouse embryo fibroblasts. Biochem Biophys Res Commun 310:824-829

30. Heath WR, Carbone FR (2013) The skin-resident and migratory immune system in steady state and memory: innate lymphocytes, dendritic cells and T cells. Nat Immunol 14:978-985

31. Herrling T, Jung K, Fuchs J (2006) Measurements of UV-generated free radicals/reactive oxygen species (ROS) in skin. Spectrochim Acta A Mol Biomol Spectrosc 63:840-845

32. Hideg É, Jansen MA, Strid Å (2013) UV-B exposure, ROS, and stress: inseparable companions or loosely linked associates? Trends Plant Sci 18:107-115

33. Higgins LG, Kelleher MO, Eggleston IM, Itoh K, Yamamoto M, Hayes JD (2009) Transcription factor Nrf2 mediates an adaptive response to sulforaphane that protects fibroblasts in vitro against the cytotoxic effects of electrophiles, peroxides and redox-cycling agents. Toxicol Appl Pharmacol 237:267-280
34. Hintze KJ, Wald KA, Zeng H, Jeffery EH, Finley JW (2003) Thioredoxin reductase in human hepatoma cells is transcriptionally regulated by sulforaphane and other electrophiles via an antioxidant response element. J Nutr 133:2721-2727

35. Hirobe T, Hasegawa K, Furuya R, Fujiwara R, Sato K (2013) Effects of fibroblast-derived factors on the proliferation and differentiation of human melanocytes in culture. J Dermatol Sci 71:45-57

36. Hseu YC, Chou CW, Kumar KJ, Fu KT, Wang HM, Hsu LS, Kuo YH, Wu CR, Chen SC, Yang HL (2012) Ellagic acid protects human keratinocyte (HaCaT) cells against UVA-induced oxidative stress and apoptosis through the upregulation of the HO-1 and Nrf-2 antioxidant genes. Food Chem Toxicol 50:1245-1255

37. Hussein MR, Haemel AK, Wood GS (2003) Apoptosis and melanoma: molecular mechanisms. J Pathol 199:275-288

38. Ishikado A, Nishio Y, Morino K, Ugi S, Kondo H, Makino T, Kashiwagi A, Maegawa H (2010) Low concentration of 4-hydroxyhexenal increases heme oxygenase-1 expression through activation of Nrf2 and antioxidative activity in vascular endothelial cells. Biochem Biophys Res Commun 402:99-104

39. Jäger E, Ringhoffer M, Altmannsberger M, Arand M, Karbach J, Jäger D, Oesch F, Knuth A (1997) Immunoselection in vivo: independent loss of MHC class I and melanocyte differentiation antigen expression in metastatic melanoma. Int $\mathbf{J}$ Cancer $71: 142-147$

40. Jakasa I, KosterE Calkoen F, McLean WHI, Campbell L, Bos JD, Verberk MM, Kezic S (2011) Skin barrier function in healthy subjects and patients with atopic dermatitis in relation to filaggrin loss-of-function mutations. $\mathrm{J}$ Invest Dermatol 131:540-542

41. Jian Z, Li K, Liu L, Zhang Y, Zhou Z, Li C, Gao T (2011) Heme oxygenase- 1 protects human melanocytes from $\mathrm{H} 2 \mathrm{O} 2$-induced oxidative stress via the Nrf2-ARE pathway. J Invest Dermatol 131:1420-1427

42. Jian Z, Li K, Song P, Zhu G, Zhu L, Cui T, Liu B, Tang L, Wang X, Wang G, Gao T, Li C (2014) Impaired activation of Nrf2-ARE signaling pathway undermines $\mathrm{H} 2 \mathrm{O} 2$-induced oxidative stress response: a possible mechanism for melanocyte degeneration in Vitiligo. J Invest Dermatol 134:2221-2230

43. Jódar L, Mercken EM, Ariza J, Younts C, González-Reyes JA, Alcaín FJ, Burón I, de Cabo R, Villalba JM (2011) Genetic deletion of Nrf2 promotes immortalization and decreases life span of murine embryonic fibroblasts. J Gerontol A Biol Sci Med Sci) 66:247-256

44. Jozkowicz A, Was H, Taha H, Kotlinowski J, Mleczko K, Cisowski J, Weigel G, Dulak J (2008) 15d-PGJ2 upregulates synthesis of IL-8 in endothelial cells through induction of oxidative stress. Antioxid Redox Sign 10:2035-2046

45. Kang BY, Kim S, Lee KH, Lee YS, Hong I, Lee MO, Min D, Chang I, Hwang JS, Park JS, Kim DH, Kim BG (2008) Transcriptional profiling in human $\mathrm{HaCaT}$ keratinocytes in response to kaempferol and identification of potential transcription factors for regulating differential gene expression. Exp Mol Med 40:208-219

46. Kannan S, Jaiswal AK (2006) Low and high dose UVB regulation of transcription factor NF-E2-related factor 2. Cancer Res 66:8421-8429

47. Kansanen E, Jyrkkänen HK, Levonen AL (2012) Activation of stress signaling pathways by electrophilic oxidized and nitrated lipids. Free Radic Biol Med 52:973-982

48. Kim J, Cha YN, Surh YJ (2009) A protective role of nuclear factor-erythroid 2- related factor-2 (Nrf2) in inflammatory disorders. Mutat Res 690:12-23

49. Kim YR, Oh JE, Kim MS, Kang MR, Park SW, Han JY, Eom HS, Yoo NJ, Lee SH (2010) Oncogenic Nrf2 mutations in 
squamous cell carcinomas of oesophagus and skin. J Pathol 220:446-451

50. Kimura M, Yamamoto T, Zhang J, Itoh K, Kyo M, Kamiya T, Aburatani H, Katsuoka F, Kurokawa H, Tanaka T, Motohashi H, Yamamoto M (2007) Molecular basis distinguishing the DNA binding profile of Nrf2-Maf heterodimer from that of Maf homodimer. J Biol Chem 282:33681-33690

51. Kimura S, Warabi E, Yanagawa T, Ma D, Itoh K, Ishii Y, Kawachi Y, Ishii T (2009) Essential role of Nrf2 in keratinocyte protection from UVA by quercetin. Biochem Biophys Res Commun 387:109-114

52. Köhle C, Bock KW (2007) Coordinate regulation of phase I and II xenobiotic metabolisms by the Ah receptor and Nrf2. Biochem Pharmacol 73:1853-1862

53. Koken SE, Greijer AE, Verhoef K, van Wamel J, Bukrinskaya AG, Berkhout B (1994) Intracellular analysis of in vitro modified HIV Tat protein. J Biol Chem 269:8366-8375

54. Kokot A, Metze D, Mouchet N, Galibert MD, Schiller M, Luger TA, Böhm M (2009) $\alpha$-Melanocyte-stimulating hormone counteracts the suppressive effect of UVB on Nrf2 and Nrf-dependent gene expression in human skin. Endocrinology 150:3197-3206

55. Konstantinopoulos PA, Spentzos D, Fountzilas E, Francoeur N, Sanisetty S, Grammatikos AP, Hecht JL, Cannistra SA (2011) Keap1 mutations and Nrf2 pathway activation in epithelial ovarian cancer. Cancer Res 71:5081-5089

56. Kuesap J, Li B, Satarug S, Takeda K, Numata I, Na-Bangchang K, Shibahara S (2008) Prostaglandin D2 induces heme oxygenase-1 in human retinal pigment epithelial cells. Biochem Biophys Res Commun 367:413-419

57. Kwak MK, Itoh K, Yamamoto M, Kensler TW (2002) Enhanced expression of the transcription factor Nrf2 by cancer chemopreventive agents: role of antioxidant response element-like sequences in the Nrf2 promoter. Mol Cell Biol 22:2883-2892

58. Lee DF, Kuo HP, Liu M, Chou CK, Xia W, Du Y, Shen J, Chen CT, Huo L, Hsu MC, Chia-Wei Li CW, Ding Q, Liao TL, Lai CC, Lin AC, Chang YH, Tsai SF, Li LY, Hung MC (2009) Keap1 E3 ligase-mediated downregulation of NF- $\mathrm{\kappa B}$ signaling by targeting IKK $\beta$. Mol Cell 36:131-140

59. Lee DJ, Kang DH, Choi M, Choi YJ, Lee JY, Park JH, Park YJ, Lee KW, Kang SW (2013) Peroxiredoxin-2 represses melanoma metastasis by increasing E-Cadherin/ $\beta$-Catenin complexes in adherens junctions. Cancer Res 73:4744-4757

60. Lee Y, Shin JM, Jang S, Choi DK, Seo MS, Kim HR, Sohn KC, Im M, Seo YJ, Lee JH, Kim CD (2014) Role of nuclear factor E2-related factor 2 (Nrf2) in epidermal differentiation. Arch Dermatol Res 306:677-682

61. Leier I, Jedlitschky G, Buchholz U, Cole SPC, Deeley RG, Keppler D (1994) The MRP gene encodes an ATP-dependent export pump for leukotriene $\mathrm{C} 4$ and structurally related conjugates. J Biol Chem 269:27807-27810

62. Li M, Xu F, Muller J, Hearing VJ, Gorelik E (1998) Ecotropic C-type retrovirus of B16 melanoma and malignant transformation of normal melanocytes. Int J Cancer 76:430-436

63. Li N, Alam J, Venkatesan MI, Eiguren-Fernandez A, Schmitz D, Di Stefano E, Slaughter N, Killeen E, Wang X, Huang A, Wang M, Miguel AH, Cho A, Sioutas C, Nel AE (2004) Nrf2 is a key transcription factor that regulates antioxidant defense in macrophages and epithelial cells: protecting against the proinflammatory and oxidizing effects of diesel exhaust chemicals. J Immunol 173:3467-3481

64. Li W, Liu H, Zhou JS, Cao JF, Zhou XB, Choi AM, Chen ZH, Shen HH (2012) Caveolin-1 inhibits expression of antioxidant enzymes through direct interaction with nuclear erythroid 2 p45related factor-2 (Nrf2). J Biol Chem 287:20922-20930
65. Lieder F, Reisen F, Geppert T, Sollberger G, Beer HD, auf dem Keller U, Schäfer M, Detmar M, Schneider G, Werner S (2012) Identification of UV-protective activators of nuclear factor erythroid-derived 2-related factor 2 (Nrf2) by combining a chemical library screen with computer-based virtual screening. J Biol Chem 287:33001-33013

66. Liu GH, Qu J, Shen X (2008) NF-кB/p65 antagonizes Nrf2-ARE pathway by depriving $\mathrm{CBP}$ from Nrf2 and facilitating recruitment of HDAC3 to MafK. Biochim Biophys Acta 1783:713-727

67. Luna-López A, Triana-Martínez F, López-Diazguerrero NE, Ventura-Gallegos JL, Gutiérrez-Ruiz MC, Damián-Matsumura P, Zentalla A, Gómez-Quiroz LE, Königsberg M (2010) Bcl-2 sustains hormetic response by inducing Nrf-2 nuclear translocation in L929 mouse fibroblasts. Free Radic Biol Med 49:1192-1204

68. Luo JL, Kamata H, Karin M (2005) IKK/NF- $\kappa B$ signaling: balancing life and death" a new approach to cancer therapy. J Clin Invest 115:2625-2632

69. Ma Q, Lu AY (2003) Origins of individual variability in P4501A induction. Chem Res Toxicol 16:249-260

70. MacLeod AK, McMahon M, Plummer SM, Higgins LG, Penning TM, Igarashi K, Hayes JD (2009) Characterization of the cancer chemopreventive Nrf2-dependent gene battery in human keratinocytes: demonstration that the Keap1-Nrf2 pathway, and not the BACH1-Nrf2 pathway, controls cytoprotection against electrophiles as well as redox-cycling compounds. Carcinogenesis 30:1571-1580

71. Maher JM, Dieter MZ, Aleksunes LM, Slitt AL, Guo G, Tanaka Y, Scheffer GL, Chan JY, Manautou JE, Chen Y, Dalton TP, Yamamoto M, Klaassen CD (2007) Oxidative and electrophilic stress induces multidrug resistance-associated protein transporters via the nuclear factor-E2-related factor-2 transcriptional pathway. Hepatology 46:1597-1610

72. Manandhar S, Cho JM, Kim J, Kensler TW, Kwak MK (2007) Induction of Nrf2-regulated genes by 3H-1,2-dithiole-3-thione through the ERK signaling pathway in murine keratinocytes. Eur J Pharmacol 577:17-27

73. Marrot L, Jones C, Perez P, Meunier JR (2008) The significance of Nrf2 pathway in (photo)-oxidative stress response in melanocytes and keratinocytes of the human epidermis. Pigment Cell Melanoma Res 21:79-88

74. Martin SF, Esser PR, Weber FC, Jakob T, Freudenberg MA, Schmidt M, Goebeler M (2011) Mechanisms of chemical-induced innate immunity in allergic contact dermatitis. Allergy 66(9):1152-1163

75. McDonald JT, Kim K, Norris AJ, Vlashi E, Phillips TM, Lagadec C, DonnaLD Ratikan J, Szelag H, Hlatky L, McBride WH (2010) Ionizing radiation activates the Nrf2 antioxidant response. Cancer Res 70:8886-8895

76. McMahon M, Itoh K, Yamamoto M, Chanas SA, Henderson CJ, McLellan LI, Wolf CR, Cavin C, Hayes JD (2001) The Cap 'n'Collar basic leucine zipper transcription factor Nrf2 (NF-E2 p45-related factor 2) controls both constitutive and inducible expression of intestinal detoxification and glutathione biosynthetic enzymes. Cancer Res 61:3299-3307

77. Mead RJ, Higginbottom A, Allen SP, Kirby J, Bennett E, Barber SC, Heath PR, Coluccia A, Patel N, Gardner I, Brancale A, Grierson AJ, Shaw PJ (2013) S[+] Apomorphine is a CNS penetrating activator of the Nrf2-ARE pathway with activity in mouse and patient fibroblast models of amyotrophic lateral sclerosis. Free Radic Biol Med 61:438-452

78. Migdal C, Botton J, El Ali Z, Azoury ME, Guldemann J, Giménez-Arnau E, Lepoittevin JP, Kerdine-Römer S, Pallardy M (2013) Reactivity of chemical sensitizers toward amino acids in cellulo plays a role in the activation of the Nrf2-ARE pathway 
in human monocyte dendritic cells and the THP-1 cell line. Toxicol Sci 133:259-274

79. Motohashi H, Katsuoka F, Engel JD, Yamamoto M (2004) Small Maf proteins serve as transcriptional cofactors for keratinocyte differentiation in the Keap1-Nrf2 regulatory pathway. Proc Natl Acad Sci USA 101:6379-6384

80. Myzak MC, Dashwood RH (2006) Chemoprotection by sulforaphane: keep one eye beyond Keap1. Cancer Lett 233:208-218

81. Natarajan VT, Singh A, Kumar AA, Sharma P, Kar HK, Marrot L, Meunier JR, Natarajan K, Gokhale RS (2010) Transcriptional upregulation of Nrf2-dependent phase II detoxification genes in the involved epidermis of vitiligo vulgaris. J Invest Dermatol 130:2781-2789

82. Natsch A (2010) The Nrf2-Keap1-ARE toxicity pathway as a cellular sensor for skin sensitizers-functional relevance and a hypothesis on innate reactions to skin sensitizers. Toxicol Sci 113:284-292

83. Niture SK, Jaiswal AK (2010) INrf2 (Keap1) targets Bcl-2 degradation and controls cellular apoptosis. Cell Death Differ 18:439-451

84. Niture SK, Jaiswal AK (2012) Nrf2 protein up-regulates antiapoptotic protein $\mathrm{Bcl}-2$ and prevents cellular apoptosis. J Biol Chem 287:9873-9886

85. Noonan FP, Zaidi MR, Wolnicka-Glubisz A, Anver MR, Bahn J, Wielgus A, Cadet J, Douki T, Mouret S, Tucker MA, Popratiloff A, Merlino G, DeFabo EC (2012) Melanoma induction by ultraviolet $\mathrm{A}$ but not ultraviolet $\mathrm{B}$ radiation requires melanin pigment. Nat Commun 3:884-894

86. Novo E, Parola M (2008) Redox mechanisms in hepatic chronic wound healing and fibrogenesis. Fibrogenes Tissue Repair $1: 1-58$

87. Okada K, Shoda J, Taguchi K, Maher JM, Ishizaki K, Inoue Y, Ohtsuki M, Goto N, Sugimoto H, Utsunomiya H, Oda K, Warabi E, Ishii T, Yamamoto M (2009) Nrf2 counteracts cholestatic liver injury via stimulation of hepatic defense systems. Biochem Biophys Res Commun 389:431-436

88. Owczarek W, Paluchowska EB, Targowski T, Nawrocka A (2011) Analiza stężeń eotaksyny 1/CCL11, eotaksyny 2/CCL24 i eotaksyny 3/CCL26 w surowicy dorosłych chorych na atopowe zapalenie skóry. Dermatol Rev Prz Dermatol 98:221-227

89. Pan H, Wang H, Wang X, Zhu L, Mao L (2012) The absence of Nrf2 enhances NF-kB-dependent inflammation following scratch injury in mouse primary cultured astrocytes. Mediators Inflamm 2012:1-9

90. Patterson AD, Carlson BA, Li F, Bonzo JA, Yoo MH, Krausz KW, Conrad M, Chen C, Gonzalez FJ, Hatfield DL (2013) Disruption of thioredoxin reductase 1 protects mice from acute acetaminophen-induced hepatotoxicity through enhanced NRF2 activity. Chem Res Toxicol 26:1088-1096

91. Pi J, Diwan BA, Sun Y, Liu J, Qu W, He Y, Styblo M, Waalkes MP (2008) Arsenic-induced malignant transformation of human keratinocytes: involvement of Nrf2. Free Radic Biol Med 45:651-658

92. Piao MS, Choi JY, Lee DH, Yun SJ, Lee JB, Lee SC (2011) Differentiation-dependent expression of $\mathrm{NADP}(\mathrm{H})$ : quinone oxidoreductase-1 via NF-E2 related factor-2 activation in human epidermal keratinocytes. J Dermatol Sci 62:147-153

93. Piao MS, Park JJ, Choi JY, Lee DH, Yun SJ, Lee JB, Lee SC (2012) Nrf2-dependent and Nrf2-independent induction of phase 2 detoxifying and antioxidant enzymes during keratinocyte differentiation. Arch Dermatol Res 304:387-395

94. Pietsch EC, Chan JY, Torti FM, Torti SV (2003) Nrf2 mediates the induction of ferritin $\mathrm{H}$ in response to xenobiotics and cancer chemopreventive dithiolethiones. J Biol Chem 278:2361-2369
95. Purdom-Dickinson SE, Sheveleva EV, Sun H, Chen QM (2007) Translational control of Nrf2 protein in activation of antioxidant response by oxidants. Mol Pharmacol 72:1074-1081

96. Rangwala SM, Li X, Lindsley L, Wang X, Shaughnessy S, Daniels TG, Szustakowski J, Nirmala NR, Wu Z, Stevenson SC (2007) Estrogen-related receptor $\alpha$ is essential for the expression of antioxidant protection genes and mitochondrial function. Biochem Bophys Res Commun 357:231-236

97. Reisman SA, Lee CY, Meyer CJ, Proksch JW, Ward KW (2014) Topical application of the synthetic triterpenoid RTA 408 activates Nrf2 and induces cytoprotective genes in rat skin. Arch Dermatol Res 306:447-454

98. Roebuck KA (1999) Regulation of interleukin-8 gene expression. J Interferon Cytokine Res 19:429-438

99. Rossi A, Kapahi P, Natoli G, Takahashi T, Chen Y, Karin M, Santoro MG (2000) Anti-inflammatory cyclopentenone prostaglandins are direct inhibitors of $\mathrm{I} \kappa \mathrm{B}$ kinase. Nature 403:103-108

100. Rothberg KG, Heuser JE, Donzell WC, Ying YS, Glenney JR, Anderson RG (1992) Caveolin, a protein component of caveolae membrane coats. Cell 68:673-682

101. Rushworth SA, Zaitseva L, Murray MY, Shah NM, Bowles KM, MacEwan DJ (2012) The high Nrf2 expression in human acute myeloid leukemia is driven by NF- $\mathrm{KB}$ and underlies its chemoresistance. Blood 120:5188-5198

102. Ryu MJ, Kang KA, Piao MJ, Kim KC, Zheng J, Yao CW, Cha JW, Hyun CL, Chung HS, Park JC, Cho SJ, Hyun JW (2014) Effect of 7, 8-dihydroxyflavone on the up-regulation of Nrf2mediated heme oxygenase-1 expression in hamster lung fibroblasts. In Vitro Cell Dev Biol Animal 50:549-554

103. Saw CL, Huang MT, Liu Y, Khor TO, Conney AH, Kong AN (2011) Impact of Nrf2 on UVB-induced skin inflammation/ photoprotection and photoprotective effect of sulforaphane. Mol Carcinog 50:479-486

104. Schafer M, Dütsch S, auf dem Keller U, Navid F, Schwarz A, Johnson DA, Johnson JA, Werner S (2010) Nrf2 establishes a glutathione-mediated gradient of UVB cytoprotection in the epidermis. Genes Dev 24:1045-1058

105. Schafer M, Willrodt AH, Kurinna S, Link AS, Farwanah H, Geusau A, Gruber F, Sorg O, Huebner AJ, Roop DR, Sandhoff K, Saurat JH, Tschachler E, Schneider MR, Langbein L, Bloch W, Beer HD, Werner S (2014) Activation of Nrf2 in keratinocytes causes chloracne (MADISH)-like skin disease in mice. EMBO Mol Med 6:442-457

106. Scharffetter-Kochanek K, Wlaschek M, Brenneisen P, Schauen M, Blaudschun R, Wenk J (1997) UV-induced reactive oxygen species in photocarcinogenesis and photoaging. Biol Chem 378:1247-1257

107. Shibata T, Ohta T, Tong KI, Kokubu A, Odogawa R, Tsuta K, Asamura H, Yamamoto M, Hirohashi S (2008) Cancer related mutations in NRF2 impair its recognition by Keap1-Cul3 E3 ligase and promote malignancy. Proc Natl Acad Sci 105:13568-13573

108. Shin JM, Kim MY, Sohn KC, Jung SY, Lee HE, Lim JW, Sooil $\mathrm{K}$, Lee YH, Im M, Seo YJ, Kim CD, Lee JH, Lee Y, Yoon TJ (2014) Nrf2 negatively regulates melanogenesis by modulating PI3 K/Akt signaling. Dermatology Conference 62: 240. PloS One 9:e96035

109. Siow RC, Ishii T, Mann GE (2007) Modulation of antioxidant gene expression by 4-hydroxynonenal: atheroprotective role of the Nrf2/ARE transcription pathway. Redox Rep 12:11-15

110. Song K, Peng S, Sun Z, Li H, Yang R (2011) Curcumin suppresses TGF- $\beta$ signaling by inhibition of TGIF degradation in scleroderma fibroblasts. Biochem Biophys Res Commun 411:821-825 
111. Talalay P, Fahey JW, Healy ZR, Wehage SL, Benedict AL, Min C, Dinkova-Kostova AT (2007) Sulforaphane mobilizes cellular defenses that protect skin against damage by UV radiation. Proc Natl Acad Sci USA 104:17500-17505

112. Tang L, Li J, Lin X, Wu W, Kang K, Fu W (2012) Oxidation levels differentially impact melanocytes: low versus high concentration of hydrogen peroxide promotes melanin synthesis and melanosome transfer. Dermatology 224:145-153

113. Temkin V, Karin M (2007) From death receptor to reactive oxygen species and c-Jun N-terminal protein kinase: the receptorinteracting protein 1 odyssey. Immunol Rev 220:8-21

114. Toosi S, Orlow SJ, Manga P (2012) Vitiligo-inducing phenols activate the unfolded protein response in melanocytes resulting in upregulation of IL6 and IL8. J Invest Dermatol 132:2601-2609

115. Tsuji G, Takahara M, Uchi H, Matsuda T, Chiba T, Takeuchi S, Yasukawa F, Moroi Y, Furue M (2012) Identification of ketoconazole as an AhR-Nrf2 activator in cultured human keratinocytes: the basis of its anti-inflammatory effect. J Invest Dermatol 132:59-68

116. Van den Bogaard EH, Bergboer JG, Vonk-Bergers M, van Vlijmen-Willems IM, Hato SV, van der Valk PG, Schroder JM, Joosten I, Zeeuwen PL, Schalkwijk J (2013) Coal tar induces AHR-dependent skin barrier repair in atopic dermatitis. J Clin Invest 123:917-927

117. Volonte D, Liu Z, Musille PM, Stoppani E, Wakabayashi N, Di YP, Lisanti MP, Kensler TW, Galbiati F (2013) Inhibition of nuclear factor-erythroid 2-related factor (Nrf2) by caveolin-1 promotes stress-induced premature senescence. Mol Biol Cell 24:1852-1862

118. Wada M, DeLong CJ, Hong YH, Rieke CJ, Song I, Sidhu RS, Yuan C, Warnock M, Schmaier AH, Yokoyama C, Smyth EM, Wilson SJ, FitzGerald GA, Garavito RM, de Sui X, Regan JW, Smith WL (2007) Enzymes and receptors of prostaglandin pathways with arachidonic acid-derived versus eicosapentaenoic acid-derived substrates and products. J Biol Chem 282:22254-22266

119. Wagner AE, Ernst I, Iori R, Desel C, Rimbach G (2010) Sulforaphane but not ascorbigen, indole-3-carbinole and ascorbic acid activates the transcription factor Nrf2 and induces phase-2 and antioxidant enzymes in human keratinocytes in culture. Exp Dermatol 19:137-144
120. Wakabayashi N, Itoh K, Wakabayashi J, Motohashi H, Noda S, Takahashi S, Imakado S, Kotsuji T, Otsuka F, Roop DR, Harada T, Engel JD, Yamamoto M (2003) Keap1-null mutation leads to postnatal lethality due to constitutive Nrf2 activation. Nat Genet $35: 238-245$

121. Wlaschek M, Tantcheva-Poór I, Naderi L, Ma W, Schneider LA, Razi-Wolf Z, Schüller J, Scharffetter-Kochanek K (2001) Solar UV irradiation and dermal photoaging. J Photoch Photobio B 63:41-51

122. Wolnicka-Glubisz A, Nogal K, Zadlo A, Plonka PM (2015) Curcumin does not switch melanin synthesis towards pheomelanin in B16F10 cells. Arch Dermatol Res 307:89-98

123. Xiao L, Du Y, Shen Y, He Y, Zhao H, Li Z (2012) TGF-beta 1 induced fibroblast proliferation is mediated by the FGF-2/ERK pathway. Front Biosci Landmark Ed 17:2667-2674

124. Yamasaki K, Gallo RL (2009) The molecular pathology of rosacea. J Dermatol Sci 55:77-81

125. Yang L, Qu M, Wang Y, Duan H, Chen P, Wang Y, Shi W, Danielson P, Zhou Q (2013) Trichostatin A inihibits TGF- $\beta$ induced reactive oxygen species accumulation and myofibroblast differentiation via enhanced Nrf2-are signaling. Mol Pharmacol 83:671-680

126. Yu M, Li H, Liu Q, Liu F, Tang L, Li C, Yuan Y, Zhan Y, Xu W, Li W, Hui Chen H, Ge C, Wang J, Yang X (2011) Nuclear factor p65 interacts with Keap1 to repress the Nrf2-ARE pathway. Cell Signal 23:883-892

127. Zhang X, Chen X, Song H, Chen HZ, Rovin BH (2005) Activation of the Nrf2/antioxidant response pathway increases IL-8 expression. Eur J Immunol 35:3258-3267

128. Zhong JL, Raval C, Edwards GP, Tyrrell RM (2010) A role for Bach1 and HO-2 in suppression of basal and UVA-induced HO1 expression in human keratinocytes. Free Radic Biol Med 48:196-206

129. Zhu H, Itoh K, Yamamoto M, Zweier JL, Li Y (2005) Role of Nrf2 signaling in regulation of antioxidants and phase 2 enzymes in cardiac fibroblasts: protection against reactive oxygen and nitrogen species-induced cell injury. FEBS Lett 579:3029-3036

130. Zhu H, Jia Z, Zhang L, Yamamoto M, Misra HP, Trush MA, Li Y (2008) Antioxidants and phase 2 enzymes in macrophages: regulation by $\mathrm{Nrf} 2$ signaling and protection against oxidative and electrophilic stress. Exp Biol Med Maywood 233:463-474 